Estudos de Psicologia

1997, Vol 14, $n^{\circ} 1,89-93$

\title{
A construção do sujeito
}

Maria Emília Lino da Silva

A construção do sujeito

\section{Maria Emília Lino da Silva}

Pontifícia Universidade Católica de Campinas

"Si, donc, dans tout les domaines, le triomphe de la vie est la création, ne devons-nous pas supposer que la vie humaine a sa raison d'être dans une création qui peut, à la différence de l'artiste et du savant, se poursuivre à tout moment chez tous les hommes: la création de soi par soi, l'agrandissement de la personalité par un effort qui tire beaucoup de peu, quelque chose de rien, et ajoute sans cesse à ce qu'ily avait de richesse dans le monde? " HBERGSON'

Retomamos a questão fundamental colocada por BERGSON, esse ilustre contemporâneo de FREUD, focalizando o que nos pareceu constituir a contribuição para o tema feita por outro francês, Jacques LACAN, apoiado em sua experiência psicanalítica. É a personalidade uma consequência de fatos aleatórios e fora de controle, ou existe a possibilidade de se assenhorear do destino, tomando-se mais autor que personagem? Como isso se toma possível? E, principalmente, em que consiste esse domínio? Ou, dito de outra forma, o que significam 'personalidade' e 'destino' e de que modo interatuam?

"Sejamos categóricos: não se trata, na anamnese psicanalítica, de realidade, mas de verdade, porque é o efeito de uma fala plena reordenar as contingências passadas dando-Ihes o sentido das necessidades a virem, tais como as constitui o pouco de liberdade por onde o sujeito as faz presente".

\footnotetext{
1 "Se, pois, em todos os domínios, o triunfo da vida é a criação, não devemos supor que a vida humana tem sua razão de ser em uma criação que, à diferença daquelas do artista e do sábio, pode ser buscada pode ser buscada a qualquer momento por todos os homens: a criação de si por si, a ampliação da personalidade por um esforço que tira muito de pouco, alguma coisa de nada, e acrescenta sem cessar ao que havia de riqueza no mundo? BERGSON, H., A alegria da criação, $p$. 24 ( tradução minha)

2 . Lacan, J., Função de campo dafala e da linguagem em psicanálise, p. 121.

Endereço para correspondência: Departamento de Pós- Graduação em Psicologia - PUCCAMP, Rua Waldemar Cesarda Silveira, 105, Swift, CEP 13045-270, Campinas, SP
} 
Três pontos parecem fundamentais nesta citação, considerados a seguir:

1. A oposição realidade-verdade. A primeira constitui-se numa sequência caótica de fatos subjetivos e/ou objetivos que se coloca totalmente fora de alcance. Já a verdade emerge como uma construção consciente, trabalhosa, em termos de uma reordenação da experiência, conferindo-lhe um sentido e uma direção.

2. O passado como contingência e o futuro como necessidade. É possível encarar tanto o passado como o futuro dentro da mesma eventualidade, o primeiro aparecendo determinado pelo acaso e o segundo, pelas necessidades. Mas é possível também, através do sentido pessoal, intimamente assumido, apoderar-se do histórico da própria vida e assim fazer-se seu senhor.

3. O presente e a liberdade do discurso. É apenas e tão somente no momento presente que se abre essa liberdade de domínio, escapando às determinações internas e exteriores. Tal portal consiste no próprio ato de tomar presente, no discurso, não só os eventos passados como aqueles ainda por suceder. É pois o instante atual que detém a chave da criatividade em termos de personalidade e destinos pessoais. É onde se encontra, também, o elo significativo a emendar o pretérito e o porvir.

." que ensinamos ao sujeito a reconhecer como seu inconsciente é a sua história"s

Ou seja, o jogo de suas determinações acrescido de um sentido que ele próprio constitui no diálogo com outro sujeito. Isto nos aparece como um resgate, ou, em outras palavras, o ser humano emergindo do determinismo da natureza não por uma negação onipotente, mas por um assumir consciente e responsável.

LACAN insiste no poder do discurso, identificando aí a força e a eficácia da psicanálise:

"seus meios são os da fala, na medida em que esta confere às funções do indivíduo um sentido; seu domínio é o do discurso concreto enquanto campo da realidade transindividual do sujeito; suas operações são as da história na medida em que ela constitui a emergência da verdade no real". ${ }^{4}$

Tal poder reside no confronto. Como toda fala supõe um ouvinte - interno/externo - a discriminação falante/ouvinte se revela criativa, porquanto gera seus dois pólos. A tensão consequente, ou o tipo de polaridade que se estabelece, reflete e define tais pólos: O-O; OS; S_S. ${ }^{5}$

No primeiro caso há um forte controle recíproco ao qual ambos se submetem, havendo um

\footnotetext{
${ }^{3}$ Lacan, J., op. Cit., p.126

${ }^{4}$ Lacan, J., op. cit., p. 122

${ }^{5}$ O: objeto: S: sujeito.
} 
esforço de manutenção do status quo. Esta paralisia Ihes aparece como essencial, posto que um elemento reflete o outro, então, negar o outro é negar a si mesmo. Já a relação O-S indica uma possível superação do impasse, posto que um pólo - S - apresenta-se livre, sendo o outro - O - que se sujeita, numa intenção implícita e inconfessa de transformar $\mathrm{S}$ em $\mathrm{O}$, de transformar O-S em O$\mathrm{O}$, por suas aparentes vantagens de situação estagnada e, portanto, sob controle.

Tal situação já admite uma resolução, na medida em que $O$ pode se rebelar contra a nãosujeição de $S$, que pode também se recusar a ser controlado por O pelo não assumir o papel de senhor que este tenta Ihe imputar. Este tipo de relação costuma acontecer em momentos muito produtivos na psicanálise, quando o analista leva o analisando a encarar a imagem que se construiu como $O$, refletindo desejos externos. Assim, ele

“... acaba por reconhecer que esse ser não passou jamais de obra sua no imaginário e que essa obra decepciona nele toda certeza. Pois nesse trabalho que faz de reconstruí-ia para um outro ele reencontra a alienação fundamental que lhe fez construir como um outro, e que a destinou a lhe ser retira a por um outro ${ }^{6}$.

De modo que a situação O-S é tensa, refletindo um equilíbrio precário e dinâmico, em que duas energias se debatem: a que se dirige para $\mathrm{O}$ e aquela tendente a $\mathrm{S}$.

No tipo de interação que esquematizamos como S-S, a relação deixa a posse e o domínio para se exercer em liberdade. A rigor, só então poderíamos falar em diálogo, embora a polaridade $\mathrm{O}-\mathrm{O}$, como uma troca de significados atribuídos, tenha também direito a participar desta conceituação tomada em sua forma mais abrangente. Espera-se que numa interação 'normal' os três tipos de esquema possam ser identificados, variando em grau e frequência ao sabor das circunstâncias, sob o predomínio da relação S-S, que implica respeito e consideração pela realidade da outra pessoa, mas que não deixa de prescindir, em muitos casos, de acordos ao nível O-O, pela sua capacidade estabilizante possibilitando respeito aos compromissos. O que surge como sinal de patologia numa relação não me parece ser exatamente o tipo de interação estabelecido, mas a rigidez em se ater a um único nível.

Por outro lado, a postura S-S aparece como a mais desejável por seu poder de permitir o diálogo no que este tem de mais genuíno: a espontaneidade e a sinceridade de duas pessoas livres. $O$ ato de dialogar implica, pois, um enorme poder intrínseco: "Mesmo se não comunica nada, o discurso representa a existência da comunicação; mesmo se nega a evidência, ele afirma que a fala constitui a verdade; mesmo se é destinado a enganar, ele especula sobre a fé no testemunho". ${ }^{7}$

\footnotetext{
${ }^{6}$ Lacan, 1., op. cit., p. 114

${ }^{7}$ Lacan, 1., op. cit., p.116.
} 
O problema concreto que efetivamente acontece na prática, dificultando a aquisição da identidade ou, em termos lacanianos, do posicionamento como sujeito no discurso substituindo o posicionamento como objeto, postura esta típica da infância e da enfermidade, levando o sujeito a se alienar no objeto de seu desejo, é o medo de se encarar face a face.

"Tal é o terror que se apodera do homem ao descobrir a figura de seu poder que dela se desvia na ação mesma que é a sua quando essa ação a mostra desnuda". ${ }^{8}$

Esse terror é bem um indício de alienação, porquanto uma proximidade mais íntima com a realidade interior o amenizaria. Contudo, a alienação mesma toma tal encontro perigoso na medida em que ameaça a miragem por ela constituída.

"Esse Ego, cuja força nossos teóricos definem agora pela capacidade de suportar a frustração, é frustração em sua essência. É frustração não de um desejo do sujeito, mas de um objeto onde seu desejo está alienado e que, quanto mais ele se elabora, mais se aprofunda para o sujeito a alienação e seu gozo ${ }^{9}$

A superação de tal situação tantálica está na assunção do próprio desejo, o que equivaleria a constituir-se como sujeito. Tal efeito resolveria o problema, na medida em que este se libertaria da dependência do objeto em que se colocou a potencial idade da satisfação, retornando assim ao desejo mesmo. Esta volta implica a reconsideração das condições internas e externas, possibilitando um novo plano de ação. Mas, como esta segunda situação se reveste de irradiações apavorantes, o ciclo pode não se quebrar e, ao invés, tornar-se vicioso.

Toda criação implica uma ruptura, e a criação de uma identidade específica, que se constitua como agente, não foge a esta regra: supõe o rompimento doloroso das identificações que de qualquer forma renderam alguma segurança no passado. Como abandonar esse trunfo precário mas conhecido, e afinal dotado de certo poder, por algo ainda mais precário, posto que dinâmico, acerca do qual não existe garantia a não ser a de que estará continuamente se reformulando, tal uma fênix?

Eu, apesar de mim - eis a apresentação do que foi capaz de construir sua identidade com as cinzas de suas identificações, ao mesmo tempo vencendo-lhes as resistências e utilizando-se delas em seu trabalho, 'num esforço que tira muito de pouco, alguma coisa de nada', acarretando como prêmio o peso da responsabilidade de seus sucessos e fracassos, que agora já não pode atribuir ao outro, porque já não pode se colocar como outro.

Mais um problema se levanta como obstáculo a esta construção: o fato de que as forças construtivas retiram seu poder da coesão e, embora isto the renda uma multiplicação de energia, tal equilibração é dinâmica e, portanto, deve ser trabalhosamente mantida. A partir disto, as forças

\footnotetext{
${ }^{8}$ Lacan, J., op. cit., p. 106.

${ }^{9}$ Lacan, J., op. cit., p. 114.
} 
destrutivas possuem um poder próprio, de modo que basta uma ação isolada para deitar abaixo todo um edifício. Uma das consequências deste fato é que aliar-se às forças desintegradoras parece prometer mais poder.

Em termos de comportamento, colocar-se como objeto e dessa posição tentar controlar o outro, assim automaticamente também objetificado, parece, a curto prazo, muito mais eficiente do que assumir a direção da própria vida e correr todos os riscos inerentes a esse domínio em nome de uma recompensa futura e, portanto, desconhecida, incerta, agravada pelo fato de que o posicionamento como sujeito libera o outro para se colocar como sujeito também, e, portanto, livre. O outro ponto é que tal 'domínio' é relativo, totalmente sem garantias, sendo mais um eterno arriscar-se e colher as consequências.

Como assinala SCHACHTEL, ${ }^{10}$ há duas tendências básicas no homem: o afeto-afetividade, impelindo-o a procurar a satisfação de seus anseios, e o afeto-enclausuramento, que tenta seduzir o ambiente para que este se encarregue desta tarefa. O primeiro leva o indivíduo a se posicionar como sujeito, o segundo detém-no na posição passiva. Esta última costuma dominar os estilos de vida, porque

"a angústia do homem ao separar-se do enclausuramento é o fator que mais se opõe a sua projeção para o mundo. Quer confiná-lo ao enclausuramento familiar de tal modo que não experimente o temor e a surpresa do infinitamente novo e desconhecido" (p.60)

Explica também porque, em tantos casos, o indivíduo desiste de procurar sua própria forma de relacionamento com o mundo, adotando integralmente o padrão imposto:

"a angústia que produz esse fenômeno é a angústia da solidão, de ser diferente dos demais, sem saber como superar esta solidão numa forma diferente da conformidade com o padrão cultural geral" (p. 61)

Já Hélio PELLEGRINO especifica que, para tolerar a posição S-S, é preciso antes aprender a tolerar a solidão, a assim colocar-se além do medo da perda e do abandono, capaz de respeitar o outro ao invés de tentar o seu domínio:

"Encontrá-lo é perdê-lo, é completá-lo na sua libérrima existência, é respeitá-lo e amá-lo em sua total e gratuita inutilidade". ${ }^{11}$

De modo que, retomando nossa questão inicial, o 'destino' pode ser uma missão ou um jugo, assim como a 'personalidade' - depende do que se é capaz de tolerar, de arriscar, de amar.

\footnotetext{
${ }^{10}$ Shachtcl, Metamorfosys

${ }^{11}$ Excerto de uma carta a Fernando Sabino, em Encontro Marcado.
} 


\section{Referências}

Bergson, H. La Conscience et la vie. In: L'Energie Spirituelle, $52^{\circ}$ ed., Presses Universitaires de France, Paris, 1949

Lacan, J. Função de campo da fala e da linguagem em psicanálise. In: Escritos, São Paulo: Perspectiva, 1978.

Shachtel. Metamorfoses, sobre el desarollo del afecto, la percepcián, la atencion y la memoria, la ed. espanhola, México/Buenos Aires, Fondo de Cultura Económica, 1962. 